\title{
Failure Analysis of the Strain Clamp Steel Anchor Corrosion of a 500 kV Transmission Line
}

\author{
Weike Liu ${ }^{1}$, Xianhui $\mathrm{Cao}^{1}$, Yujing $\mathrm{Hu}^{1 *}$, Dong $\mathrm{Li}^{2}$, $\mathrm{Yi} \mathrm{Xie}^{1}$ \\ ${ }^{1}$ State Grid Hunan Electric Power Company Limited Research Institute, Changsha, Hunan, 410007, China \\ ${ }^{2}$ State Grid Changde Maintenance Company, Changde, Hunan, 415000, China
}

\begin{abstract}
By macroscopic observation, composition analysis, mechanical properties test, SEM, energy spectrum, overall grip tensile test and finite element mechanics calculation method, the strain clamp steel anchor corrosion failure of a $500 \mathrm{kV}$ transmission line is analysed. The results show that the corrosion of steel anchor for 31 years are the result of the natural corrosion, steel anchor corrosion rate is accelerated due to the galvanic corrosion, crevice corrosion, stress and damaged surface of the galvanized layer, and achieve C4 environment (zinc 2.1-4.2 um per year, carbon steel 50-80 um per year). The hardware are qualified. It is suggested to replace the steel anchor with yellow rust on the surface after 5 years, and to reevaluate the next maintenance cycle of the gold fittings without yellow rust on the surface at present, and replace it when the corrosion depth reaches $10 \%$. Before replacement, all fittings should be monitored, especially steel anchor.
\end{abstract}

\section{Introduction}

High Voltage Power Transmission is the main way of modern power transmission for long distance. Strain clamp is widely used in high power grid construction as an important power tool. The strain clamp can be divided into two parts: steel anchor and aluminum tube. The main function is to fix the transmission wire to bear its tension and fix it on the strain string group or the tower. Due to the bad working environment, the clamp is easy to be damaged in the process of using, and the failure of the clamp caused by construction defects, design problems and bad operating environment occurs from time to time $[1,2]$.

In this paper, the corrosion failure of a $500 \mathrm{kV}$ transmission line steel anchor on strain clamp was investigated and analysed. The corrosion causes were analysed through macroscopic inspection, mechanical performance test, SEM and energy spectrum test. To evaluate the current service status, grip and pull test on the corroded strain clamp and tests on the wire, jumper, strain string and suspension clamp were carried out; the corrosion velocity estimation and mechanical calculation of steel anchor were used to propose replacement. This is the first time in the industry to find and evaluate the corrosion status of $500 \mathrm{kV}$ steel anchor, which provides a technical reference for the investigation and analysis of such faults.

\section{Analysis background}

A $500 \mathrm{kV}$ transmission line was overhauled in September
2019 for power failure. During the overhauling, the operator of the transmission line in the tower found that the steel anchor of the strain clamp in tower \#292 was seriously corroded, and part of the gold string was also corroded, as shown in figure 1.The line operation and maintenance unit shall check the three groups of strain string, suspension string and strain clamps of Tower No. 68, Tower No. 109 and Tower No. 292, the first section of C-phase jumper of Tower No. 68 and the first section of B-phase traverse of Tower No. 109 (close to B-phase strain clamps), among which the strain clamps are NY300/40, jumpers are LGJQ-300/40 and conductors are LGJQ-300/40.The line was put into operation in 1988 and has been in operation for 31 years. There is no replacement record during the period of inspection pole tower fittings. In this fault, the steel anchor is corroded seriously, and the steel anchor and its related fittings and wires may not meet the service requirements of mechanical properties, which poses a threat to the safety and stability of the transmission network, so it is urgent to be evaluated and dealt with.

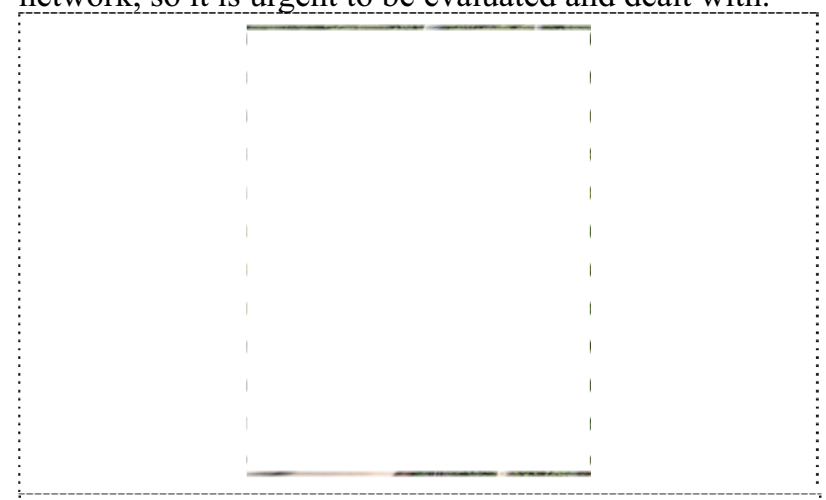

Figure 1. Corrosion of strain clamp steel anchor and fittings.

\footnotetext{
*Corresponding author's e-mail: yjhu1@mail.buct.edu.cn
} 


\section{Test}

\subsection{Inspection appearance of steel anchor}

The exposed surfaces of three groups of strain clamp steel anchors of Tower No. 68, 109 and 292 are all seriously corroded and have complex shapes, which are not convenient for anticorrosion coating, as shown in figure 2 . Steel anchor rings are welded.

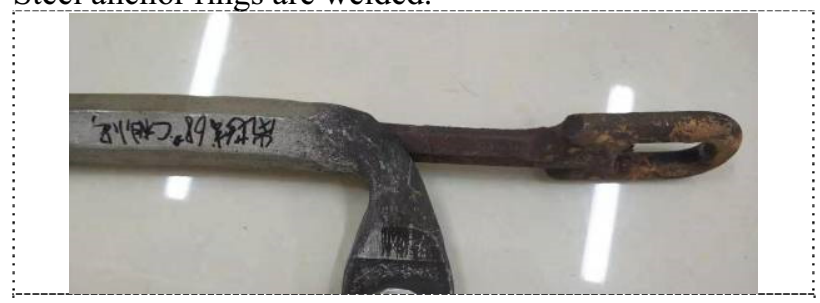

Figure 2. Surface morphology of exposed steel anchor with no. 68 tower strain clamp.

\subsection{Internal inspection of steel anchor}

The steel anchor inside the aluminum bushing was found to be in good condition, and no traces of rust were found, as shown in figure 3 . The thickness of galvanized layer of the uncorroded steel anchor was measured to meet the standard requirements. The steel core of the conductor in the strain clamp steel anchor is not corroded except at the point where the steel ring is inserted, and the steel core in the compression zone is not corroded, which will not affect the grasping strength performance of the compression zone, as shown in figure 4.

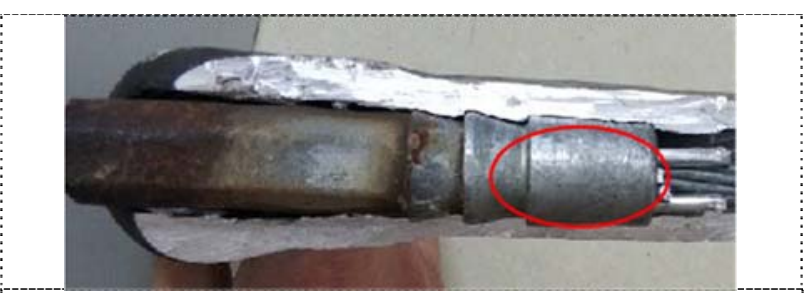

Figure 3. There is no rust on the surface of the steel anchor inside the aluminum casing.

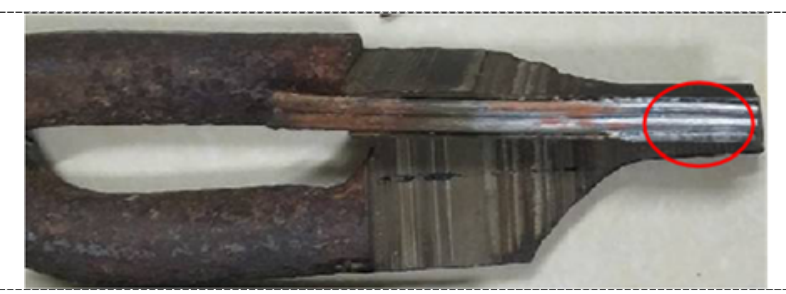

Figure 4. The steel core in the compression zone is not corroded.

\subsection{Steel anchor composition, hardness, tensile properties test}

The material of tower No. 109 B phase strain clamp steel anchor is Q235A. Its composition, hardness, yield strength and tensile strength meet the standard requirements.

\subsection{SEM and energy spectrum analysis of corroded surface}

SEM analysis was conducted on the corrosion surface of the anchor steel ring zone of tower No. 109 Phase B strain clamp steel anchor, and it was found that the surface was cracked and porous, showing typical surface morphology of rust, as shown in figure 5. No S element was detected on the surface by energy spectrum, excluding the influence factor of environmental accelerated corrosion, as shown in table 1 .

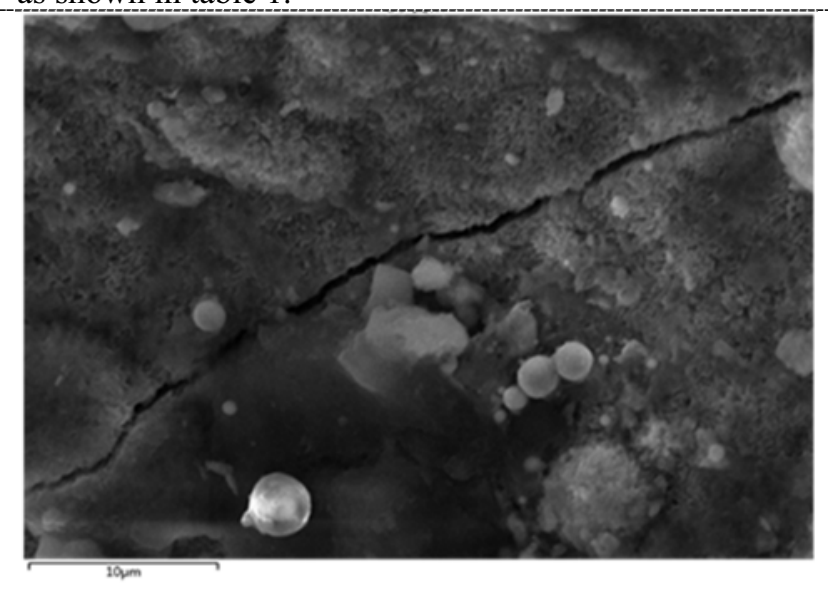

Figure 5. The surface cracks and porosity of the ring area of steel corroded by steel anchor in B phase of Tower No. 109.

Table 1. \#94 tower cable angle.

\begin{tabular}{ccc}
\hline Element & Wt.\% & At.\% \\
\hline $\mathrm{Fe}$ & $81.39 \pm 0.43$ & 59.46 \\
$\mathrm{O}$ & $13.15 \pm 0.36$ & 33.54 \\
$\mathrm{~K}$ & $1.74 \pm 0.13$ & 1.81 \\
$\mathrm{Si}$ & $1.03 \pm 0.13$ & 1.49 \\
\hline
\end{tabular}

\subsection{Overall grip tensile test}

The overall grip tensile test was carried out on the small side strain clamp of Phase B of Tower 109. This strain clamp was qualified.

\subsection{Corrosion environment and corrosion life estimation of steel anchor}

According to the corrosion map, it is located in C3 environment (Zinc 0.7-2.1 um/year, carbon steel 25-50 um/year) [3], but the corrosion of strain clamp steel anchor is more serious, and the corrosion rate is higher than that of other fittings, as shown in figure 6 . The original padding of the steel anchor is $19 \mathrm{~mm}$, and the current padding is $17.8-18.4 \mathrm{~mm}$, and the corrosion rate reaches $\mathrm{C} 4$ environment (zinc 2.1-4.2 um/year, carbon steel 50-80 um/year). The reasons are as follows :(1) the steel anchor contacts with the aluminum casing, and there is the corrosion of the dissimilar metal couple. (2) Crack corrosion exists in the gap between steel anchor and aluminum casing, the weld at the end of steel anchor, and the gap between steel anchor and steel core. (3) Accelerated corrosion of steel anchor under tensile stress. (4) The galvanized layer on the hydraulic rear surface of 
the steel anchor is damaged.

Based on the finite element analysis calculation of Abaqus, when the edge of steel anchor is reduced to $17.2 \mathrm{~mm}$, the force of steel anchor is greater than the material strength requirement, that is, the service of steel anchor should meet the requirement that the edge is larger than $17.2 \mathrm{~mm}$. At present, the thinnest part is $17.8 \mathrm{~mm}$. Based on the corrosion rate of low carbon steel in the $\mathrm{C} 4$ environment of 50-80 um/year, it is recommended to replace the steel anchor covered with yellow rust after 5 years.

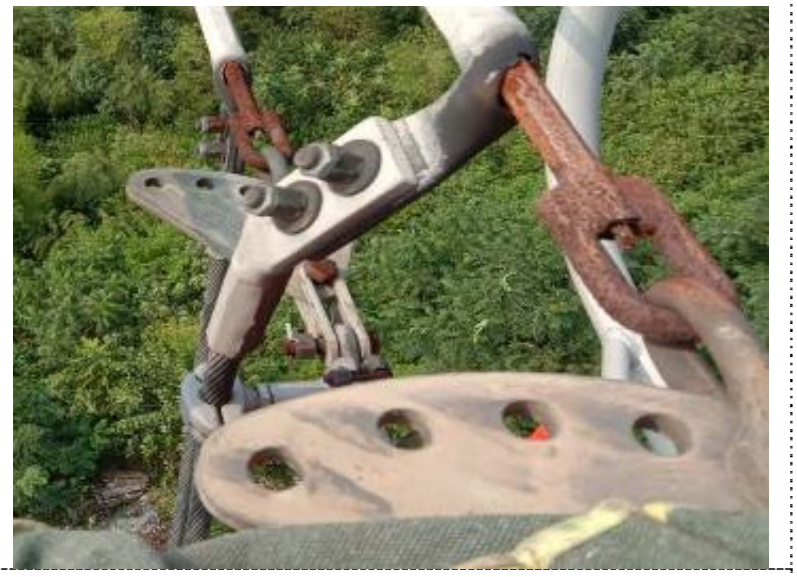

Figure 6. Comparison of corrosion of tensile steel anchor with other metal fittings.

\subsection{Wire, jumper, strain string, suspension clamp test}

The test shows that the B phase wire of tower No. 109 and the $\mathrm{C}$ phase jumper of tower No. 68 are qualified. The overall tensile test was carried out, and the strain strings and suspension clamp of tower No. 68 passed.

\section{Analyse and discussion}

Firstly, the causes of anchor corrosion were analyzed. The test results show that the composition, hardness and tensile properties of the steel anchor meet the standard requirements, and the thickness of the galvanized layer of the uncorroded part meets the standard requirements after cutting the strain clamp, which indicates that the initial state of the steel anchor is qualified. SEM and energy spectrum analysis showed that the typical surface rust did not contaminate the environment with high $\mathrm{S}$ and $\mathrm{P}$ which could accelerate the corrosion. The reason why the steel anchor corrosion is more serious than other metal fittings is because of the dissimilar metal electrocouple corrosion, crack corrosion, tensile stress accelerated corrosion and the damage of galvanized layer on the hydraulic rear surface. It is concluded that the steel anchor corrosion is the result of natural corrosion in 31 years.

Then the corrosion environment and corrosion life are evaluated. According to the corrosion depth analysis of steel anchor, the corrosion rate of steel anchor reached C4, and the corrosion rate was 2.1-4.2 um/year of zinc coating and 50-80 um/year of carbon steel. The overall grip tensile test shows that the strain clamp of steel anchor corrosion still meets the service conditions. Combined with the finite element mechanical calculation, it is estimated that the edge distance of the steel anchor in service shall be greater than $17.2 \mathrm{~mm}$, and the thinnest place measured is $17.8 \mathrm{~mm}$ at present. Based on the corrosion rate of carbon steel in the $\mathrm{C} 4$ environment of 50-80 um/year, it is recommended to replace the steel anchor covered with yellow rust after 5 years.

Although some of the conductor, jumper, strain strings and suspension clamps of the tower were rusted, the test results met the standard requirements and they could run normally.

\section{Conclusions and Suggestions}

\subsection{Conclusions}

(1) The corrosion of steel anchor for inspection is the result of natural corrosion in 31 years. Under the condition of galvanic corrosion, crevice corrosion, tensile stress and hydraulic surface damage, the corrosion rate of steel anchor is accelerated to reach $\mathrm{C} 4$ environment.

(2) Although the corrosion of steel anchor is serious, it still has not reached the replacement condition.

(3) Wire, jumper wire and fittings string for inspection are qualified.

\subsection{Suggestions}

(1) Based on the test and calculation of the steel anchor, it is suggested that the steel anchor covered with yellow rust should be replaced after 5 years, and the steel anchor with the rod transfer plan can be replaced in advance in combination with the renovation project. The current surface is not covered with yellow rust for the next maintenance cycle to re-evaluate. It should be replaced when the corrosion depth reached $10 \%$. Before replacement, all fittings should be monitored and especially steel anchor corrosion should be closely monitored.

(2) The corrosion rate of steel anchor is higher than that of other fittings. The thickness of galvanized layer of newly replaced steel anchor should be increased to more than $120 \mathrm{~mm}$. The metal detection of newly replaced fittings and bolts should be strengthened to ensure the quality of zinc plating. After the installation of new steel anchor, an anti-corrosion coating should be carried out immediately to strengthen the protection and meet the requirements of DL/T 1453-2015 Anticorrosive Protection Coating of Transmission Line Tower [4].

\section{References}

1. Cai X H. Analysis on $500 \mathrm{kV}$ Compact Transmission Line Strain Clamps Fracturing Accident [J]. North China Electric Power, 2003(03):26-28.

2. Li X H, Wu H L, Ding H, et al. Simulation and failure 
analysis of strain clamp failed caused by deterioration of contact resistance[C]. Recent Advances in Structural Integrity Analysis - Proceedings of the International Congress (APCF/SIF-2014), 2014:212217.

3. National Energy Bureau. The technical codes of anticorrosion protection for metallic material in the transformer substation: DL/T 1425-2015[S]. Beijing: China Electric Power Press, 2015.

4. National Energy Bureau. Anticorrosive coating of transmission line steel tower: DL/T 1453-2015[S]. Beijing: China Electric Power Press, 2015. 